Hyrdrogen Energy

https://doi.org/10.52825/thwildauensp.v1i. 10

(C) Authors. This work is licensed under a Creative Commons Attribution 4.0 International License

Published: 15 June 2021

\title{
Hydrogen and Usability of Hydrogen Storage Technologies
}

\author{
Liquid Organic Hydrogen Carriers (LOHC) versus \\ other Physical and Chemical Storage Methods
}

Lutz B. Giese ${ }^{1}$ and Jörg Reiff-Stephan 1[https://orcid.org/0000-0003-4176-6371]
${ }^{1}$ Technical University of Applied Sciences Wildau, Germany

\begin{abstract}
Science, technology and politics agree: hydrogen will be the energy carrier of the future. It will replace fossil fuels based on a sufficient supply from sustainable energy. Since the possibilities of storing and transporting hydrogen play a decisive role here, the so-called LOHC (Liquid Organic Hydrogen Carriers) can be used as carrier materials. LOHC carrier materials can reversibly absorb hydrogen, store it without loss and release it again when needed. Since little or no pressure is required, normal containers or tanks can be used. The volume or mass-related energy densities can reach around a quarter of liquid fossil fuels.

This paper is to give an introduction to the field of hydrogen storage and usage of those $\mathrm{LOHC}$, in particular. The developments of the last ten years have been related to the storage and transport of hydrogen with LOHC. These are crucial to meet the future demand for energy carriers e.g. for mobile applications. For this purpose, all transport systems are under consideration as well as the decentralized supply of rural areas with low technological penetration, e.g. regions of Western Africa which are often characterized by a lack of energy supply. Hydrogen bound in LOHC can provide a hazard-free alternative for distribution. The paper provides an overview of the conversion forms as well as the chemical carrier materials. Dibenzyltoluene as well as $\mathrm{N}$-ethylcarbazole - as examples for LOHC - are discussed as well as chemical hydrogen storage materials like ammonia boranes as alternatives to LOHC.
\end{abstract}

Keywords: hydrogen storage, LOHC, climate-neutral mobility

\section{Introduction}

Renewable energy sources are important sources of electricity, and the expansion of renewables is one of the central pillars in Germany's energy transition. The energy supply is to become more climate-friendly, and is also to make us less dependent on imports of fossil fuels. In this context, hydrogen is the renewable energy carrier of the future [1],[2]. If it is produced from renewable electricity, it is climate-friendly, storable and transportable over long distances. It thus contributes to sector coupling - a key concept of the energy transition and becomes the basis for climate-neutral mobility, industry and heat supply. In addition, the development and marketing of hydrogen technology has the potential to become a driver of the German economy. However, there are currently only a few German hydrogen and fuel cell products on the market. One reason for this is the complexity of hydrogen value chains: This complexity means high risk, especially for first movers in the industry and for small and medium-sized enterprises (SMEs). For them, creating economies of scale is crucial to reduce manufacturing costs and develop an internationally competitive industry for green hydrogen applications in Germany [3]. 
Liquid organic hydrogen carriers (LOHC) technology turn hydrogen into a secure power storage technology. LOHC hydrogen storage systems use liquid hydrogen carrier media, which can be used to store and transport hydrogen at ambient temperature. The advantages of LOHC are that hydrogen is stored at high energy density and that the existing distribution infrastructure of liquid fuels can be used. As a result, LOHC represents another option for efficient hydrogen storage that reduces hydrogen volume and stores hydrogen safely. Figure 1 describes the broad applicability of LOHC, particularly in use for medium-term storage systems. It thus describes an excellent basis for use, especially for mobile applications.

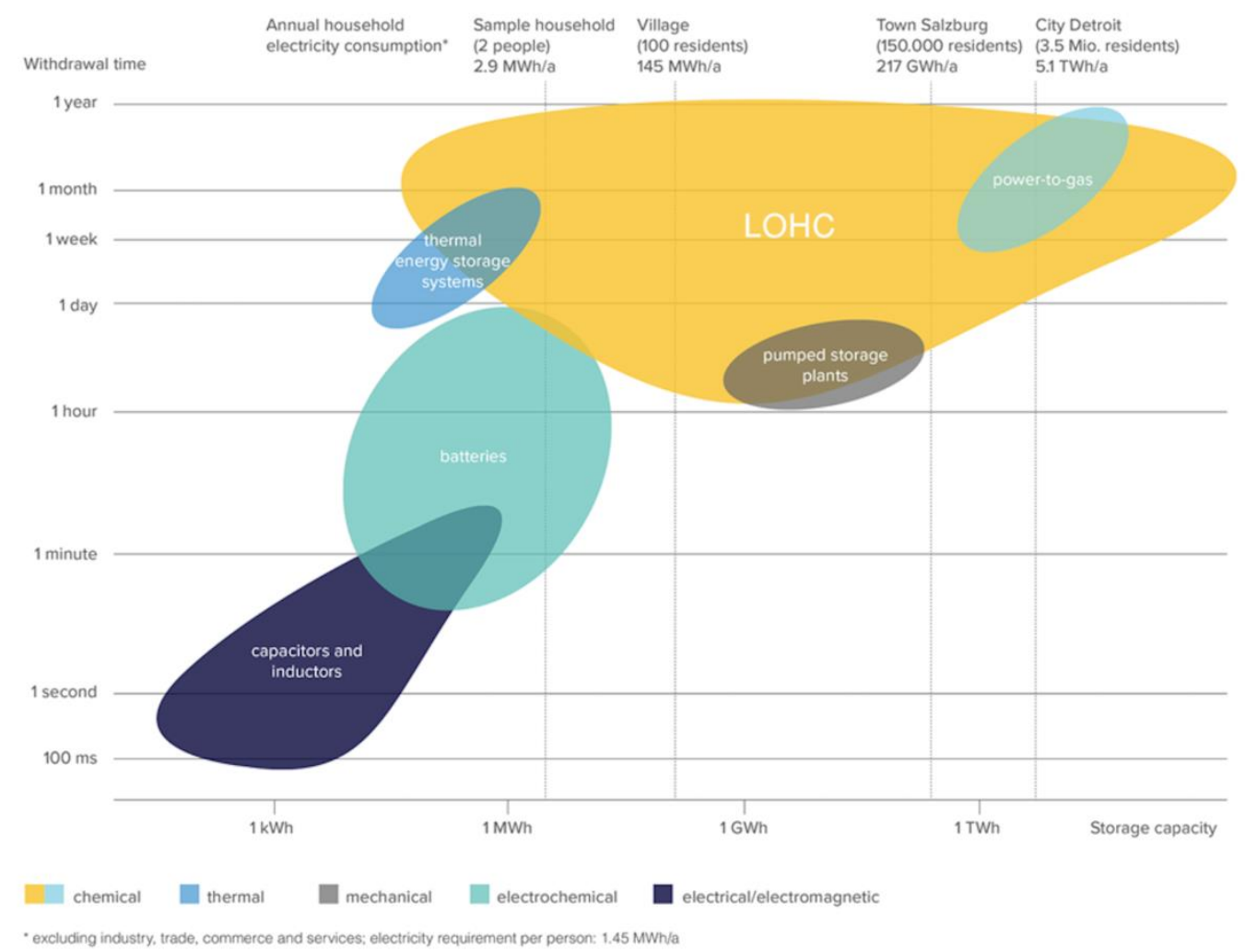

Figure 1. LOHC compared to other storage materials [4].

\section{Fundamentals}

According to the Federal Ministry for Economic Affairs and Energy, in 2019, Germany still used around $87 \%$ of its primary energy based on conventional energy sources - e.g. fossil natural gas [5]: it mainly consists of methane $\left(\mathrm{CH}_{4}\right)$ - and thus - like all fossil energy sources it releases climate-damaging carbon dioxide when burned (see equation 1):

$$
\mathrm{CH}_{4}(\mathrm{~g})+2 \mathrm{O}_{2}(\mathrm{~g}) \rightarrow \mathrm{CO}_{2}(\mathrm{~g}) \uparrow+2 \mathrm{H}_{2} \mathrm{O}(\mathrm{g}) \uparrow
$$

One kilogram of methane - that is approximately 1.4 standard cubic meter $\mathrm{CH}_{4}$ - has a sensible enthalpy of combustion (lower calorific value) of $50,140 \mathrm{~kJ}$ - this corresponds to $13.9 \mathrm{kWh}$ [6]. Taking into account the primary energy rucksack, the emission factor of natural gas is $0.22 \mathrm{~kg} \mathrm{CO}_{2}$ per $\mathrm{kWh}$ of fuel energy (calorific value).

On the contrary, one kilogram of hydrogen - that is equivalent of 11 standard cubic meters $\mathrm{H}_{2}$ - has a sensible enthalpy of combustion (lower calorific value) of $120,900 \mathrm{~kJ}$ - this corresponds to $33.6 \mathrm{kWh}$ - and only releases water during combustion or an electrochemical conversion in a fuel cell (see equation 2; compare table 1 [7],[8]):

$$
2 \mathrm{H}_{2}+\mathrm{O}_{2} \rightarrow 2 \mathrm{H}_{2} \mathrm{O}
$$


Table 1. Properties of hydrogen [7],[8].

\begin{tabular}{|l|l|l|}
\hline Property & Value & Unit \\
\hline Density (as gas) & 0.0899 & $\mathrm{~kg} / \mathrm{Nm}^{3}$ (per standard cubic meter) \\
\hline Density (as liquid) & 70.79 & $\mathrm{~kg} / \mathrm{m}^{3}$ (per cubic meter of liquid) \\
\hline Lower calorific value & 3.0 & $\mathrm{kWh} / \mathrm{Nm}^{3}$ (per standard cubic meter) \\
\hline & 33.6 & $\mathrm{kWh} / \mathrm{kg}$ (by weight) \\
\hline Upper calorific value & 3.5 & $\mathrm{kWh} / \mathrm{Nm}^{3}$ (per standard cubic meter) \\
\hline & 39.4 & $\mathrm{kWh} / \mathrm{kg}$ (by weight) \\
\hline
\end{tabular}

Hydrogen is seen today as an important energy carrier of the future. However, due to the energy source and the following process steps, there is $\mathrm{CO}_{2}$ footprint, as well. The catalytic steam reforming of fossil fuels to hydrogen and other gases is still important today (see town gas, synthesis gas, Haber-Bosch process for ammonia synthesis, etc.; equations 3 and 4):

$$
\begin{aligned}
& \text { I. } \mathrm{CH}_{4}(\mathrm{~g})+\mathrm{H}_{2} \mathrm{O}(\mathrm{g}) \rightarrow 3 \mathrm{H}_{2}(\mathrm{~g})+\mathrm{CO}(\mathrm{g}) \\
& \text { II. } \mathrm{CO}(\mathrm{g})+\mathrm{H}_{2} \mathrm{O}(\mathrm{g}) \rightarrow \mathrm{H}_{2}(\mathrm{~g})+\mathrm{CO}_{2}(\mathrm{~g})
\end{aligned}
$$

Also electrolysis methods, such as PEMEL, AEL, or SOEC, are traditional ways of producing hydrogen [8] (see equation 5):

$$
2 \mathrm{H}_{2} \mathrm{O}+\mathrm{W}_{\mathrm{el}} \rightarrow 2 \mathrm{H}_{2} \uparrow+\mathrm{O}_{2} \uparrow
$$

In 2019, renewable energies contributed around $14.9 \%$ to primary energy consumption in Germany [5]. While the contribution to heat and, in particular, to mobility still was low, in 2017 nearly $33 \%$ of gross electricity generation was provided from renewable sources (see figure 2). Wind energy, bioenergy and photovoltaics play an important and growing role, but because of fluctuations they temporarily and increasingly generate surpluses that have to be put to use. Under the term "Power-to-X", the generation of hydrogen via electrolysis is likely to play an important role in the future.

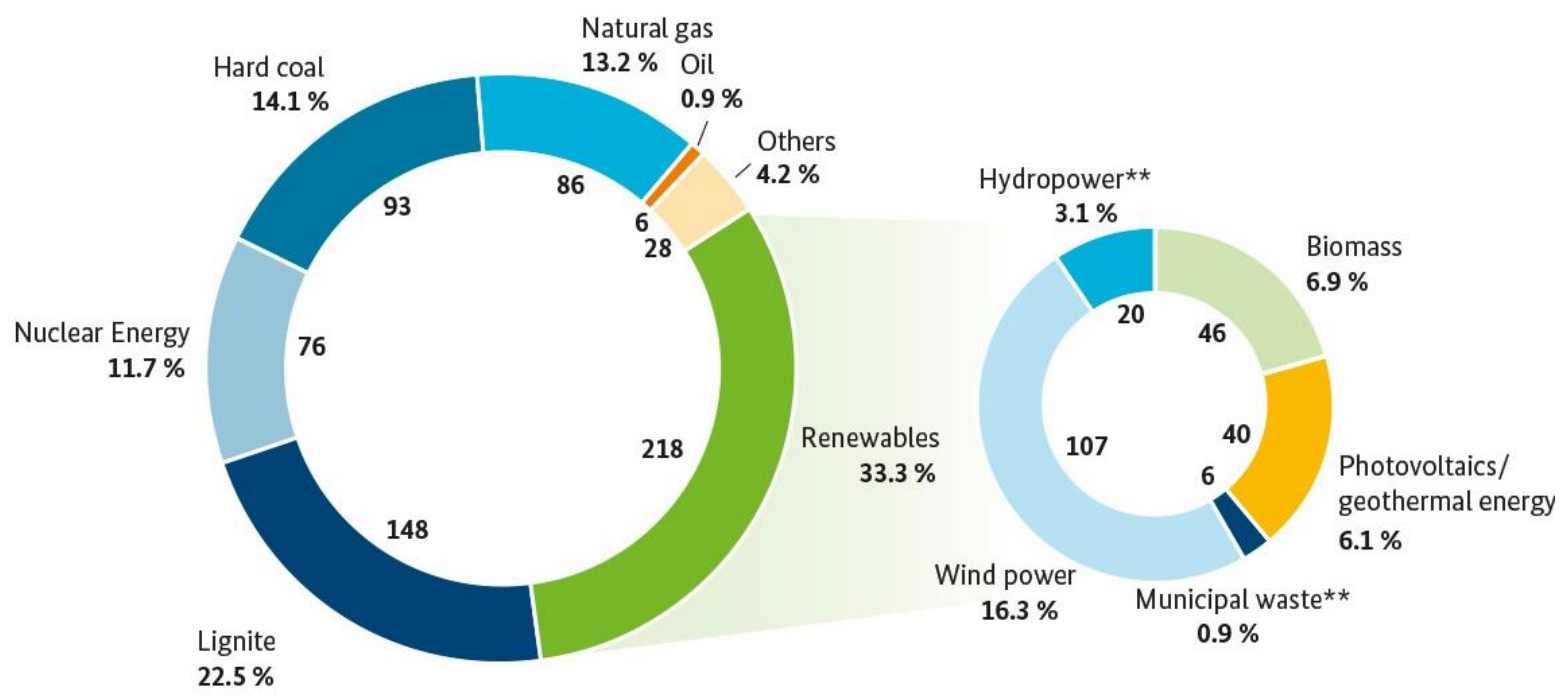

Figure 2. Energy data - gross electricity generation in Germany 2017 (total 654.8 TWh) [3].

In addition to the generation, the transport, possibly storage and use of the generated hydrogen are central issues [8]. In principle, the uptake of hydrogen or reform methane in the existing natural gas networks (natural gas $\mathrm{H}$, limited admixture of $\mathrm{H}_{2}$ ) is possible. Later, either the mixture can be used directly or the hydrogen is separated from the mixture again - using suitable methods. 
A transfer of physically compressed hydrogen by means of transport is also possible, e.g.

- compressed,

- liquefied under pressure, or

- cryo-adsorptively bound.

However, the chemical compression of hydrogen is very interesting, because it enables high storage densities to be generated in a simple manner, both in terms of volume and weight [9]. The following ways are possible:

- Salt-like hydrides of the alkali or alkaline earth metals

- Other substances such as methanol or formic acid as products via synthesis gas

- Aromatics, boranes and the like as LOHC carrier materials by means of reversible hydrogenation

\section{Principle of Energy Storage via Hydrogen with LOHC Materials}

LOHC carrier materials can reversibly absorb hydrogen, store it without loss and release it again when needed. Since little or no pressure is required, normal containers or tanks can be used. The volume or mass-related energy densities are higher than with conventional electrochemical storage devices (accumulators) and can reach around a quarter of the energy densities of liquid fossil fuels [10].

The following is a brief explanation of the process sequence (see figure 3 ).

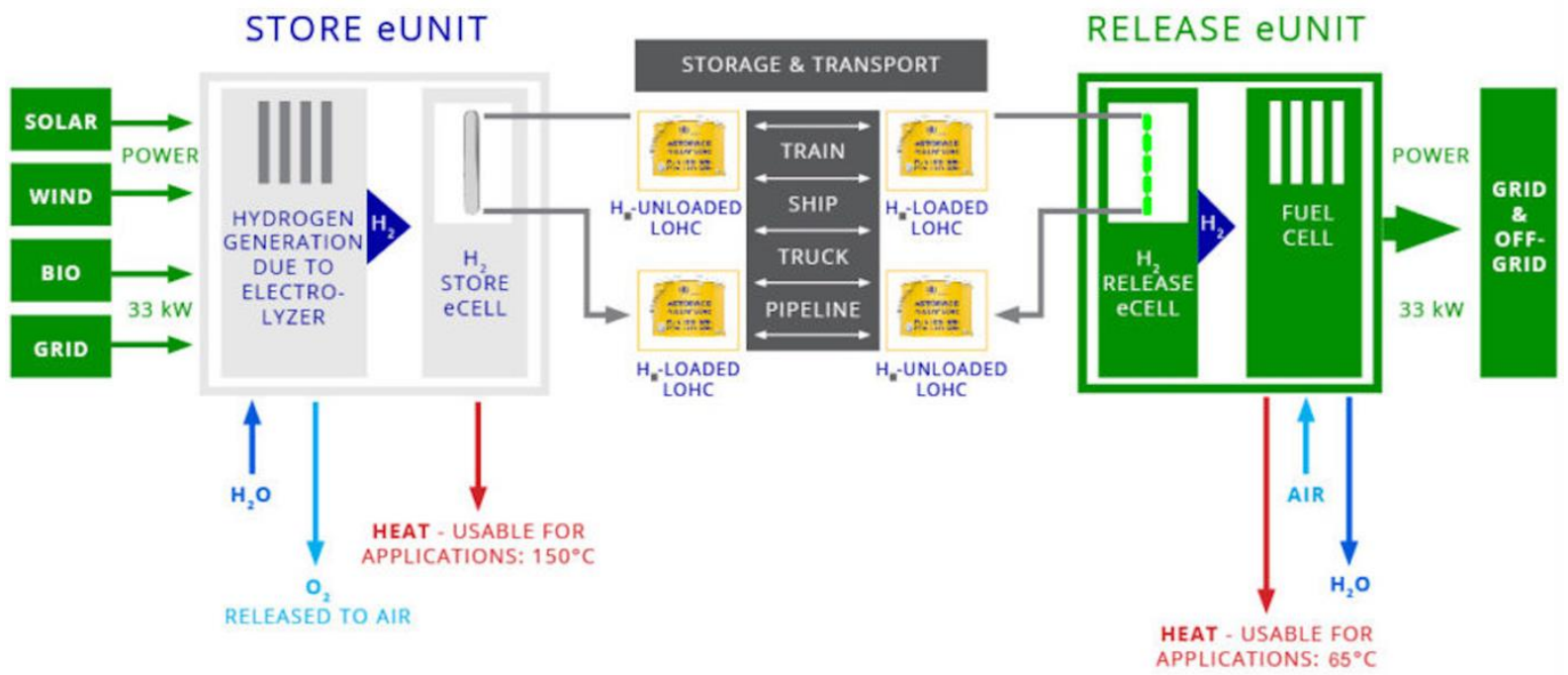

Figure 3. Scheme of the chemical storage of regenerative electricity via hydrogen with the aid of a reversible hydrogenation reaction of

e.g. polyaromatics such as $\mathrm{N}$-ethylcarbazole or hydrogen storage [4].

If fluctuating, electricity from RES is generated in excess at times of low load in the grid, this excess could endanger the stability of the grid frequency and thus the safe grid operation. As an alternative to activating generation systems for renewable electricity, in addition to conversion into useful heat (via power-to-heat, e.g. with heat pumps), generation of hydrogen via electrolysis can be useful. As shown in figure 3, the hydrogen for the hydrogenation of suitable LOHC carrier materials can in the meantime be chemically bound and thus stored without loss, in order then to be used again after dehydrogenation. Mobile as well as stationary applications, in particular in combined heat and power, are possible here.

The hydrogen can be converted into mechanical energy, electrical energy and/ or heat using internal combustion engines, gas turbines or fuel cells. The electrical energy generated can be used on site, be used to charge plug-in electric vehicles or to be fed into the grid. 
Emerging heat can serve as space heat, hot water heat or process heat as well as for the hydrogenation/ dehydrogenation process of the LOHC itself.

\section{Important Carrier Materials for Chemical Hydrogen Storage}

The following carriers for reversible hydrogen storage should be briefly discussed:

- LOHC carrier materials

- Other materials

\section{LOHC Carrier Materials for Chemical Hydrogen Storage}

The abbreviation LOHC means "Liquid Organic Hydrogen Carrier". This is a liquid, organic carrier material based on fossil petroleum or natural gas today. LOHC compounds can also be sustainably generated in the future on the basis of renewable energies, e.g. biomass. The $\mathrm{LOHC}$ carrier material is not consumed or is only consumed to a small extent during application, but thus can be used over many cycles.

Disadvantages of hydrogen transport or hydrogen storage using LOHC materials compared to pipelines are the higher transport costs due to the additional mass of the carrier, larger storage volumes due to the energy density and, last but not least, often the need to store groundwater hazardous substances with all the associated expense. LOHC is a fossilfuel-based carbon compound (e.g. dibenzyltoluene).

The following LOHC carriers should be discussed (for organic chemistry compare [11]):

- Dibenzyltoluene $\mathrm{C}_{21} \mathrm{H}_{20}$

- $\quad$-ethylcarbazole $\mathrm{C}_{14} \mathrm{H}_{13} \mathrm{~N}$

- Toluene $\mathrm{C}_{7} \mathrm{H}_{8}$

\section{Dibenzyltoluene}

Dibenzyltoluene $\mathrm{C}_{21} \mathrm{H}_{20}$ is a polyaromatic and is suitable for storing hydrogen via a hydrogenation and dehydrogenation reaction (see figure 4). There are several structural similar isomers of this compound. Around $50 \mathrm{~kg}$ of hydrogen can be stored per ton of carrier.

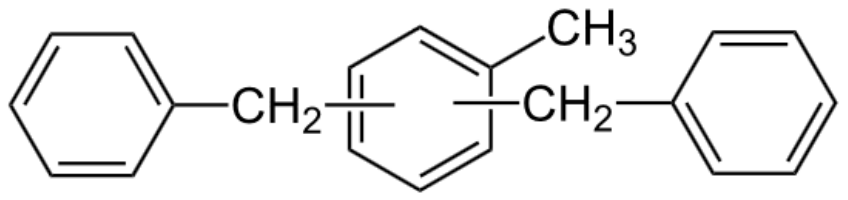

Figure 4. Dibenzyltoluene (polyaromatic) for hydrogen storage via a reversible hydrogenation reaction [12].

According the magazine $\mathrm{HZ}$ wei from 2016 , the carrier absorbs the hydrogen at $150^{\circ}$ to $250^{\circ} \mathrm{C}$ in the reactor, while the catalyst here is ruthenium [13]. One litre of LOHC can store 600 I of gaseous hydrogen, which means the energy density is $1.9 \mathrm{MWh}$ per cubic meter of LOHC. The reversible loading and unloading cycle can be carried out around 1,000 times. The density is $1,050 \mathrm{~kg} /$ standard cubic meter, the LOHC can be stored indefinitely.

Using for simplification the Ideal Gas Law (see equation 6; [6]),

$$
p * V=n * R * T
$$

with

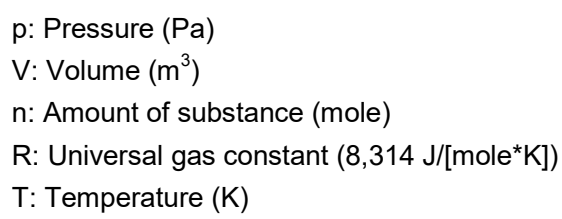


the energy density can be roughly calculated for control purposes:

- 600 standard cubic meters hydrogen/ standard cubic meters LOHC (=1.05 t LOHC)

According to the Ideal Gas Law, 600 standard cubic meters of hydrogen correspond to

- $600,000 \mathrm{l} /(22.4 \mathrm{l} / \mathrm{mole})=26.79 * 10^{3} \mathrm{~mole} \mathrm{H}_{2}=53.6 \mathrm{~kg} \mathrm{H}_{2}$

Thus, the specific hydrogen loading on the carrier is

- $53.6 / 1050=5.1 \%$ by weight.

A complete hydrogenation of dibenzyltoluene according to the reaction (see equation 7 )

$$
\mathrm{C}_{21} \mathrm{H}_{20}+9 \mathrm{H}_{2} \rightarrow \mathrm{C}_{21} \mathrm{H}_{33}
$$

would result in a maximum specific hydrogen loading on the carrier of

- $6.2 \%$ by weight, that would be $65.1 \mathrm{~kg} \mathrm{H}_{2}$ per standard cubic meter LOHC (or per 1.05 ton LOHC).

However, with the specific sensible enthalpy of combustion (lower calorific value) of

- $120,900 \mathrm{~kJ} / \mathrm{kg} \mathrm{H} \mathrm{H}_{2}=33.6 \mathrm{kWh} / \mathrm{kg} \mathrm{H}$,

the energy density of the LOHC dibenzyltoluene at 600 standard cubic meters of hydrogen per standard cubic meter of LOHC is around

- $1,800 \mathrm{kWh}$ per standard cubic meter LOHC (= 1.8 MWh without burning the carrier), or $1,715 \mathrm{kWh}$ per ton LOHC

\section{N-Ethylcarbazole}

Another example of a suitable process is the catalytic hydrogenation and dehydrogenation of $\mathrm{N}$-ethylcarbazole $\left(\mathrm{C}_{14} \mathrm{H}_{13} \mathrm{~N}\right.$ ) or similar compounds (such as $\mathrm{N}$-ethylcarbazole or phenylene carbazole; see figure 5).

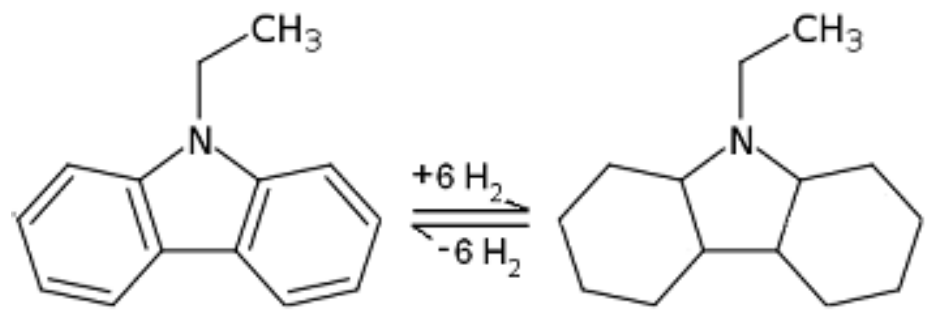

Figure 5. Principle of the chemical storage of hydrogen generated by renewable electricity with the help of a reversible

hydrogenation reaction of polyaromatics such as $N$-ethylcarbazole [14].

In an exothermic chemical reaction under increased pressure and temperature, the compound is hydrogenated with hydrogen to form the perhydro compound catalytically at temperatures above $100^{\circ} \mathrm{C}$ (see equation 8):

$$
\mathrm{C}_{14} \mathrm{H}_{13} \mathrm{~N}+6 \mathrm{H}_{2} \rightarrow \mathrm{C}_{14} \mathrm{H}_{25} \mathrm{~N}
$$

The maximum specific hydrogen loading would be

- $12 / 207=5.8 \%$ by weight 
with a complete hydrogenation according to the above equation, that would be around $58 \mathrm{~kg} \mathrm{H}_{2}$ per ton of loaded LOHC. Information on measured values is not available, but it is estimated that similar, if somewhat lower, volume and mass-related energy densities than with dibenzyltoluene can be achieved with $\mathrm{N}$-ethylcarbazole.

\section{Toluene (to Methylcyclohexane)}

Another possibility for reversible hydrogen storage is the hydrogenation/ dehydrogenation of toluene $\mathrm{C}_{7} \mathrm{H}_{8}$ to methylcylohexane. This process is known as methylcyclohexane-toluene$\mathrm{H}_{2}$ system (MTH). Toluene is a widely used solvent that is suspected of being carcinogenic. Because of the difficulty in dehydrogenation, research has shifted to other substances.<smiles>Cc1ccccc1CCCCC1CCCCC1</smiles>

Figure 6. Dihydrogenation reaction from methylcyclohexane to the aromatic toluene (1-methyl-benzene) for the reversible storage of hydrogen with the aid of the hydrogenation reaction [15].

According to the reaction (see equation 9)

$$
\mathrm{C}_{7} \mathrm{H}_{8}+3 \mathrm{H}_{2} \rightarrow \mathrm{C}_{7} \mathrm{H}_{14}
$$

the maximum specific hydrogen loading would be

- $6.1 \%$ by weight, so that would result in around $61 \mathrm{~kg}$ of hydrogen per ton of loaded LOHC.

\section{Other Chemical Hydrogen Storage Materials}

The following substances are also named as potential hydrogen carriers:

- Ammonia boranes

- Hydrocarbons

- Formic acid

- Methanol

While ammonia boranes starting from $\mathrm{NBH}_{4}$ (or $\mathrm{NBH}_{6}$ in the hydrogenated state) or $\mathrm{C}_{4} \mathrm{NBH}_{12}$ sometimes achieve values of over $10 \%$ by weight hydrogen loading, they are considered to be rather difficult to handle.

The reforming and re-reforming (= ADAM \& EVA process, canned can process) from methane to hydrogen and vice versa takes place via synthesis gas $\left(=\mathrm{CO} / \mathrm{H}_{2}\right.$ mixture) according to the equations 3 and 4 . In technology, this process is used for energy transport and can also be seen as a kind of chemical hydrogen carrier process. In addition, it is the first stage of the Fischer-Tropsch synthesis. On this basis, partially or completely sustainable methane can be made from hydrogen, which was obtained regeneratively via electrolysis, e.g. using (i) $\mathrm{CO}_{2}$ from fossil waste/ flue gases after sequestration (CCS, $\mathrm{CCU}$ ), or more sustainably (ii) after recovery of $\mathrm{CO}_{2}$ from the air or (iii) after separation from biogas. Conversion into hydrogen is possible in the opposite direction.

The synthesis gas process, in conjunction with the methanol synthesis (III, see below) and the Fischer-Tropsch synthesis (I and II, see below), enables the production of (i) 
alcohols such as methanol, (ii) dimethyl ether (DME, from methanol), (iii) light, medium and heavy hydrocarbons (e.g. petrol), as well as other energy carriers (e.g. formic acid) [9],[16]. The preferred carbon source (input) is sustainable $\mathrm{CO}_{2}$ (e.g. from biogas) or other biomass.

The synthesis gas process initially generates $\mathrm{CO} / \mathrm{H}_{2}$ mixtures, which can then be converted into gaseous and liquid hydrocarbons or $\mathrm{C} / \mathrm{H} / \mathrm{O}$ compounds. Catalysts made of cobalt or iron are used here, at around $160^{\circ}-300^{\circ} \mathrm{C}$ and up to 25 bar. The following reaction schemes I to III can occur, among others (equations 10a to 15):

I. Alkanes - chains (e.g. $\mathrm{n}=8$ : petrol [octane])

$$
\begin{aligned}
& \mathrm{nCO}+(2 \mathrm{n}+1) \mathrm{H}_{2} \rightarrow \mathrm{C}_{\mathrm{n}} \mathrm{H}_{2 \mathrm{n}+2}+\mathrm{n} \mathrm{H}_{2} \mathrm{O} \\
& 8 \mathrm{CO}+17 \mathrm{H}_{2} \rightarrow \mathrm{C}_{8} \mathrm{H}_{18}+8 \mathrm{H}_{2} \mathrm{O}
\end{aligned}
$$

II. Alkenes - chains; alkanes - rings (e.g. $n=6$ : cyclohexane)

$$
\begin{aligned}
& \mathrm{n} \mathrm{CO}+(2 \mathrm{n}) \mathrm{H}_{2} \rightarrow \mathrm{C}_{\mathrm{n}} \mathrm{H}_{2 \mathrm{n}}+\mathrm{n} \mathrm{H}_{2} \mathrm{O} \\
& \mathrm{CO}+12 \mathrm{H}_{2} \rightarrow \mathrm{C}_{6} \mathrm{H}_{12}+6 \mathrm{H}_{2} \mathrm{O}
\end{aligned}
$$

III. Alcohols (e.g. $\mathrm{n}=1$ : methanol)

$$
\begin{aligned}
& \mathrm{n} \mathrm{CO}+(2 n) \mathrm{H}_{2} \rightarrow \mathrm{C}_{n} \mathrm{H}_{2 n+1} \mathrm{OH}+(\mathrm{n}-1) \mathrm{H}_{2} \mathrm{O} \\
& \mathrm{CO}+2 \mathrm{H}_{2} \rightarrow \mathrm{CH}_{3} \mathrm{OH}
\end{aligned}
$$

Further specific reactions can be:

IV. Methane (compare equations 3, 4 and 10a)

$$
\mathrm{CO}+3 \mathrm{H}_{2} \rightarrow \mathrm{CH}_{4}+\mathrm{H}_{2} \mathrm{O}
$$

V. Formic acid

$$
\mathrm{CO}+\mathrm{H}_{2} \mathrm{O} \rightarrow \mathrm{HCOOH}
$$

VI. Dimethyl ester (DME)

$$
2 \mathrm{CH}_{3} \mathrm{OH} \rightarrow \mathrm{CH}_{3} \mathrm{OCH}_{3}+\mathrm{H}_{2} \mathrm{O}
$$

Formic acid $\mathrm{HCOOH}$ (see equation 14) is a hazardous substance that can catalytically split off hydrogen, but is also rather difficult to handle. Methanol $\mathrm{CH}_{3} \mathrm{OH}$ (see equation 12b) is widely used as a solvent in industry. It can be obtained via the so-called methanol synthesis using synthesis gas, which today mainly comes from the reforming of fossil natural gas according to equations 3 and 4 . Methanol would rather be burned or can be used advantageously in fuel cells of the DMFC type (Direct Methanol Fuel Cell). In synthesis it can be used to produce DME (see equation 15) or for transesterification of rapeseed oil into biodiesel (FME, fatty acid methyl ester).

\section{Conclusions}

Science and technology as well as politics agree: Hydrogen is the energy carrier of the future, which can and will probably replace fossil energy carriers, especially natural gas, and will increasingly replace them by the middle of the century. A sufficient supply of sustainable energy from regenerative sources is of course decisive for climate protection. However, logistical steps are of crucial importance for this conversion of the energy supply. In addition to the production via e.g. electrolysis, the possibilities of storing and transporting hydrogen naturally play a decisive role. In the future, LOHC will be used as a carrier material for this purpose, e.g. in hydrogen storage systems to supply stationary, decentralized electricity storage systems with fuel. However, LOHC can also be used in the form of mobile hydrogen storage systems for hydrogen-based mobility. For example, hydrogen from electrolysis could 
be stored in suitable locations and then be transported to the respective consumption points such as hydrogen filling stations or the chemical industry. This procedure can supplement and support the distribution of hydrogen via pipelines or pressurized gas containers. Because of the technical requirement to convert to hydrogen, the use of LOHC as a pressureless, transportable and storable carrier material is of great importance.

The aim of this work was therefore to give an overview of the possibilities of storing hydrogen in so-called LOHC systems. In fact, the analysis has shown that there are (i) a large number of different types of carriers and conversion methods, e.g. via the FischerTropsch synthesis, but also that (ii) we already have flexible carrier materials with acceptable energy densities that can substitute liquid fossil fuels. Therefore, it will be important in the next few years to further investigate these possibilities, e.g. for mobility with hydrogen, and ultimately to make them usable.

\section{References}

[1] Teichmann D, Stark K, Müller K, Zöttl G, Wasserscheid P, Arlt W. Energy storage in residential and commercial buildings via Liquid Organic Hydrogen Carriers (LOHC). Energy \& Environmental Science. 2012;5(10):9044. https://doi.org/10.1039/c2ee22070a

[2] Hodoshima S, Takaiwa S, Shono A, Satoh K, Saito Y. Hydrogen storage by decalin/naphthalene pair and hydrogen supply to fuel cells by use of superheated liquid-filmtype catalysis. Applied Catalysis A: General. 2005 04;283(1-2):235-242. https://doi.org/10.1016/j.apcata.2005.01.010

[3] Renewable Energy. https://www.bmwi.de/Redaktion/EN/Dossier/renewable-energy.html. Accessed 2021 February 23.

[4] LOHC Technology Turns Hydrogen into a Secure Power Storage Technology. https://h2industries.com/en/technologyl. Accessed 2021 February 03.

[5] Energiedaten - nationale und internationale Entwicklung. www.bmwi.de. Accessed 2021 February 20.

[6] Brdička R. Grundlagen der physikalischen Chemie. Berlin: VEB Dt. Verl. d. Wiss.; 1985.

[7] Töpler J, Lehmann J, eds. Hydrogen and Fuel Cell: Technologies and Market

Perspectives. Berlin, Heidelberg: Springer; 2017. https://doi.org/10.1007/978-3-662-44972-1

[8] Gribova M. Transition of the Fossil Energy Supply into the Hydrogen Based Economy of the Future. TH Wildau; 2020.

[9] Sterner M, Stadler I, eds. Energiespeicher - Bedarf, Technologien, Integration. 2 ed.. Springer; 2017.

[10] Sievi G, Geburtig D, Skeledzic T, Bösmann A, Preuster P, Brummel O, Waidhas F, Montero MA, Khanipour P, Katsounaros I, Libuda J, Mayrhofer KJJ, Wasserscheid P.

Towards an efficient liquid organic hydrogen carrier fuel cell concept. Energy \&

Environmental Science. 2019;12(7):2305-2314. https://doi.org/10.1039/c9ee01324e

[11] Schirmeister T, Schmuck C, Wich P. Beyer/Walter Organische Chemie . 25. ed.. Hirzel; 2016.

[12] Mixture of Several Structural Isomers of Dibenzyltoluene. https://commons.wikimedia.org/wiki/User:J\%C3\%BC. Accessed 2021 February 21.

[13] Geitmann S. LOHC - Eine Pfandflasche für Wasserstoff. https://www.hzwei.info/blog/2016/05/11/lohc-eine-pfandflasche-fuer-wasserstoff. Accessed 2016 February 20.

[14] Cüppers P. Reaction N-Carbazol / Perhydro-N-Carbazol. https://commons.wikimedia.org/wiki/File:Perhydro-N-Carbazol.PNG. Accessed 2021

February 21. 
[15] Mattern R. Synthese von Toluol mit Methylcyclohexan als Zwischenstufe. https://commons.wikimedia.org/wiki/File:Toluol-Synthese.svg. Accessed 2021 February 21.

[16] Kainer F. Die Kohlenwasserstoff-Synthese nach Fischer-Tropsch. 1. ed. . Springer (reprint 2014); 1950. 